\title{
Aging, inflammation, stem cells, and bone healing
}

Emmanuel Gibon ${ }^{1,2,3}$, Laura Lu ${ }^{1}$ and Stuart B. Goodman ${ }^{\text {* }^{*}}$

\begin{abstract}
Complex interactions among cells of the monocyte-macrophage-osteoclast lineage and the mesenchymal stem cell-osteoblast lineage play a major role in the pathophysiology of bone healing. Whereas the former lineage directs inflammatory events and bone resorption, the latter represents a source of cells for bone regeneration and immune modulation. Both of these lineages are affected by increasing age, which is associated with higher baseline levels of inflammatory mediators, and a significant reduction in osteogenic capabilities. Given the above, fracture healing, osteoporosis, and other related events in the elderly present numerous challenges, which potentially could be aided by new therapeutic approaches to modulate both inflammation and bone regeneration.
\end{abstract}

\section{Background}

Most developed countries are facing an aging population. Currently, persons over 65 years of age represent $13 \%$ of the American population [1], and this number is expected to grow as the "Baby Boomer" generation continues to age beyond 65 [2]. By 2030, they are projected to represent $16.9 \%$ of the population; this segment will increase to $25.8 \%$ by 2060 [3]. The changing demographics of the world's population have wide-ranging implications that include a shift in medical needs.

Bone fractures are among the most common orthopedic problems that require medical intervention, particularly in the elderly. Almost half of fractures are related to osteoporosis, especially in individuals over the age of 55 [4]. Beyond the impact on the health and quality of life of individual patients, fractures are expensive and present a multi-billion-dollar cost to society because of direct and indirect costs [4]. With an increasingly aging population, a

\footnotetext{
* Correspondence: goodbone@stanford.edu

'Department of Orthopaedic Surgery, Stanford University, R1 16, 300 Pasteur

Drive, Stanford, CA 94305, USA

Full list of author information is available at the end of the article
}

better understanding of how bone repair changes with age is critical in developing and optimizing effective therapeutic treatments.

Bone healing is a complex process. After bone injury, a stage of inflammation is necessary for progression to healing. In vivo studies have shown early secretion of pro-inflammatory factors such as interleukin (IL)-1 and IL-6, tumor necrosis factor-alpha (TNF $\alpha$ ), macrophage colony-stimulating factor (M-CSF), and inducible nitric oxide synthase (iNOS) [5]. In a study of double TNF $\alpha$ gene knockout mice $\left(p 55^{-1-} / p 75^{-1-}\right)$, Gerstenfeld et al. [6] showed that pro-inflammatory signals are required for proper bone repair, as these mice failed to initiate intramembranous bone formation and had markedly reduced expression of type 1 collagen and osteocalcin mRNA. Moreover, Xing et al. [7], using $C C R 2^{-/-}$mice, have shown that inflammation is critical to bone healing; when the CCR2-monocyte chemotactic protein-1 (CCR2-MCP-1) chemokine-receptor axis was interfered with, inflammation and bone healing were impaired.

Bone marrow macrophages (also called osteal macrophages) are also important for the repair of bone by coordinating the crosstalk between osteoclasts and osteoblasts [8]. Furthermore, using the macrophage Fas-induced apoptosis (MAFIA) transgenic model, Cho et al. [9] showed that osteal macrophages mediated parathyroid hormonedependent bone regeneration. Other studies also reported the important role of osteal macrophages in the processes of bone healing [10-12].

Beyond pro-inflammatory signals, macrophages also secrete many growth factors and chemokines that are critical during the inflammatory phase of bone healing $[6,13]$. These growth factors include transforming growth factor-beta (TGF $\beta$ ), insulin-like growth factor (IGF), fibroblast growth factor (FGF), and platelet-derived growth factor (PDGF). Macrophages also secrete chemokines, such as MCP-1 and monocyte inflammatory protein 1 alpha (MIP-1 $\alpha$ ), that are essential for mesenchymal stem cell (MSC) homing and migration to the injured site [14]. 
In addition to macrophages, MSCs are critical for bone regeneration. MSCs are multipotent and can differentiate into many cell types, including chondrocytes and osteoblasts for endochondral and intramembranous ossification, respectively [14]. A key step in bone healing is the localization of MSCs to the site of injury. For example, in a parabiosis model, Shinoara et al. [15] demonstrated that the stromal cell-derived factor 1/CXCR4 (SDF-1/CXCR4) ligand-receptor axis is critical for the homing of progenitor cells that participate in fracture healing. Similarly, Kitaori et al. [16] used an exchanginggraft and autograft mouse model to show that SDF-1 ${ }^{+/-}$ and $\mathrm{CXCR}^{+/-}$are important to the recruitment of MSCs during skeletal repair. Many other studies have confirmed the beneficial role of MSCs in bone regeneration $[17,18]$. Nevertheless, the origin of the MSCs that are directly involved in fracture healing is controversial. Colnot et al. [19] showed that periosteum and endosteum are primary sources of MSCs for fracture repair. Similarly, using a parabiotic mouse model, Kumagai et al. [20] showed little to no contribution of circulating cells to direct repair of the injured bone. At a minimum, systemically migrated MSCs and osteoprogenitors are thought to play an important paracrine role, modulating both inflammation and subsequent bone repair.

Given the above, there appears to be a deficiency in our understanding of the interactions between macrophages and MSCs in bone healing, especially in the elderly population. Specifically, aging may alter these interactions and thereby play an important role in the elderly patient's ability for regeneration of musculoskeletal tissues. This review will address the effect of aging on both macrophages and MSCs as it relates to bone healing. Figure 1 summarizes the effect of aging on MSCs and macrophages.

\section{The concept of macrophage polarization}

Bone injury leads to the production of pro-inflammatory cytokines and chemokines and to systemic recruitment of macrophage precursors to the injury site [21]. As such, it is important to understand the different macrophage populations that play a role in bone repair. Though they exist within a spectrum, macrophages can be broadly described as uncommitted M0, pro-inflammatory $\mathrm{M} 1$, and antiinflammatory M2 populations [22]. Mantovani et al. [23] have shown that these designations are similar in humans and mice. M0 macrophages can be polarized to proinflammatory M1 macrophages by interferon-gamma (IFNY) and lipopolysaccharide (LPS) via Toll-like receptors (TLRs) like TLR-4, whereas both M0 and M1 macrophages can be polarized to an anti-inflammatory M2 phenotype by exposure to IL-4 [24, 25]. M1 macrophages are characterized by a cytokine release profile of $\mathrm{TNF} \alpha$, IL-6, IL-1, IL-12, IL-23, Oncostatin M (OSM), and type 1 IFN with increased expression of iNOS, CCR7, and HLADR $[26,27]$. Alternatively, the M2 cytokine release profile includes IL-4, IL-10, IL-13, and IL-1ra and increased expression of CD206, Ym1 (eosinophil chemotactic factor), CD163, CCL1, CCL18, FIZZ1, Arginase 1, and chitotriosidase $[28,29]$. In actuality, both in humans and mice, there probably exists a spectrum of polarization phenotypes, with a general preponderance of pro- versus anti-inflammatory properties. With these multiple phenotypes, macrophages play several roles within the bone-

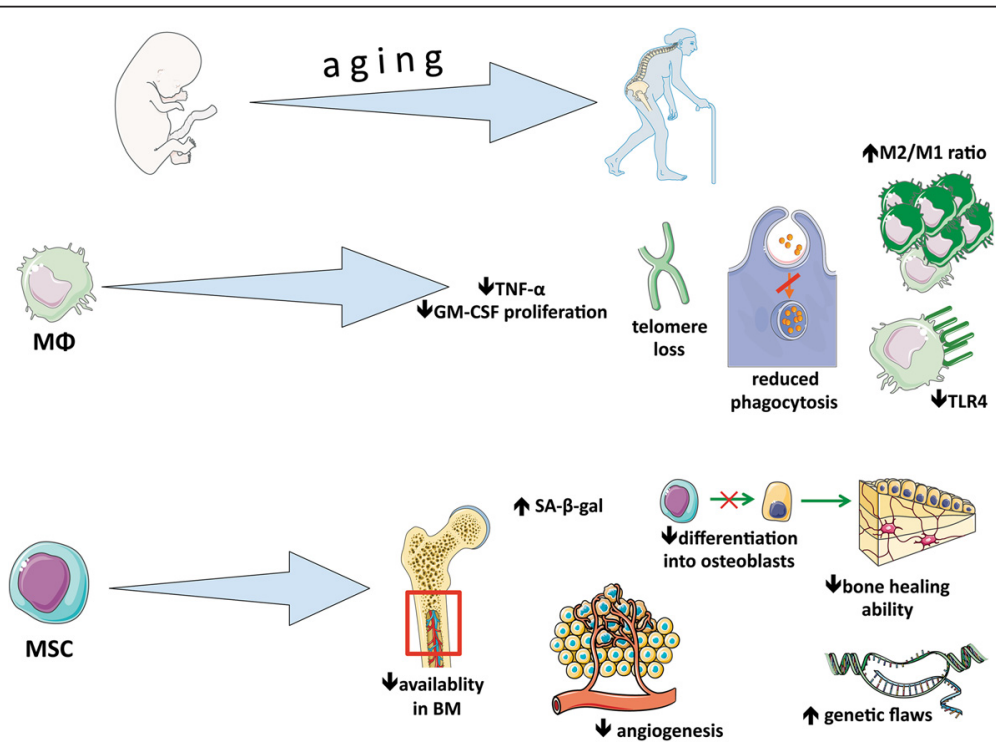

Fig. 1 The effect of aging on mesenchymal stem cells and macrophages. $\uparrow$ increase, $\downarrow$ decrease, BM bone marrow, GM-CSF granulocyte macrophage colony-stimulating factor, MФ macrophage, MSC mesenchymal stem cell, SA- $\beta$-gal senescence-associated $\beta$-galactosidase, TLR4 Toll-like receptor 4 , TNF-a tumor necrosis factor-alpha 
healing process, depending on their polarization status and environmental cues. For instance, in humans, retrieved periprosthetic tissues revised because of loosening and osteolysis demonstrated increased M1/M2 macrophage ratios [25].

\section{Aging and macrophages}

Macrophages are essential components of the innate and adaptive immune systems, in the maintenance of physiological homeostasis, and in bone remodeling [11]. As these cells play an important role in a wide variety of processes, a clear knowledge of how macrophages function and how they change with age is crucial for understanding both healthy and pathological states.

\section{Intrinsic changes with aging}

Although it is apparent that macrophages have altered activities with age, it is unclear as to what these specific changes entail and the mechanisms that drive such changes in musculoskeletal tissues. Several studies point to intrinsic factors that alter macrophage polarization, function, and survival. Wang et al. [30] found that aged murine muscle had higher levels of M2a polarized macrophages, muscle fibrosis, and collagen accumulation. The increased frequency of M2a macrophages and fibrosis was attributable to the aging of myeloid lineage cells, as demonstrated by rescue of aged muscle with infusion of young bone marrow cells [30]. Interestingly, inducing muscle-specific neuronal nitric oxide synthase (nNOS) was sufficient to prevent increased M2a frequency and arginase-1-dependent fibrosis [30]. Shortening of telomeres in aged macrophages also contributes to macrophage susceptibility to oxidative stress and reduced granulocyte macrophage colony-stimulating factor (GM-CSF)-dependent proliferation [31]. These cellular defects were found in aged and telomerase knockout $\left(\mathrm{Terc}^{-/-}\right)$mice; Sebastian et al. concluded that telomere loss caused reduced STAT5a oxidation and phosphorylation and ultimately impairment of GM-CSF-dependent macrophage proliferation [31]. Similarly, increased levels of S-endoglin, a transmembrane glycoprotein associated with inflammatory processes, were associated with decreased macrophage proliferation, decreased survival response to GM-CSF, increased oxidative stress, and skewed myeloid cell polarization toward an M2 phenotype [32]. Chitotrioside, a marker for chronically activated macrophages and inflammation, has also been shown to be elevated in older humans [33]. Herrero et al. demonstrated that, at the genomic level, aged macrophages have decreased DNA-binding activity in the promoter region of the $I A \beta$ gene, resulting in decreased expression of major histocompatibility complex (MHC) class II molecules [34]. As evidenced by the changes described above, aging alters many aspects of macrophage survival and function.

\section{Aging microenvironment}

In addition to intrinsic changes of aging, macrophages are modulated by their aging microenvironment and a poorly described number of external factors. When challenging young macrophages with aged serum, Gomez et al. found reduced macrophage secretion of TNFa and increased basal levels of IL-6 [35]. Though the group did not specifically identify the factors contributing to these observations, they concluded that, owing to heat resistance of the effect, the stimulatory factor(s) for increased IL-6 production was not a protein [35]. In a study comparing phagocytosis by young and aged peritoneal macrophages and bone marrow-derived macrophages (BMDMs), Linehan et al. demonstrated that older peritoneal macrophages have significantly impaired phagocytosis compared with younger macrophages; however, there was no evident defect in phagocytosis for aged BMDM [36]. Moreover, they found that injection of young peritoneal macrophages into the peritoneal cavities of aged mice led to impaired phagocytosis and increased levels of T and B cells [36]. Barrett et al. found that glial cells exposed to conditioned media from aged BMDMs challenged with IFNY or LPS had increased expression of pro-inflammatory mediators [37]. Such a pro-inflammatory environment could further mediate increased inflammation by infiltrating macrophages and thus contribute to a cascade of cellular damage [37]. Together, these findings suggest a profound influence of the aging microenvironment on macrophage function.

\section{Inflamm-aging}

Aging is also associated with elevated levels of secreted inflammatory cytokines beyond the previously described functional and environmental changes [38]. Much of the literature describes aged macrophage hypersensitivity and increased responsiveness to inflammatory signals. For example, when aged BMDMs are challenged with IFN $\gamma$ or LPS, they increase their expression of arginase and secrete characteristic pro-inflammatory M1 and Th1 cytokines, such as TNF $\alpha$, NOS2, IL-1 $\beta$, and IFN $\gamma$ [30, 37, 39]. Moreover, aged macrophages increase their surface density of TLR4, the receptor for LPS, permitting a faster and enhanced inflammatory response [40]. Similarly, Smallwood et al. found that aged macrophages have increased nitric oxide production under resting conditions as well as enhanced bactericidal activity against Salmonella [41]. These findings suggest that aged macrophages remain in a pre-activated resting state that enhances their response to exposure of pro-inflammatory stimuli [41]. However, with increased production of reactive oxygen species, aged macrophages are susceptible to oxidative damage [41]. Although there is increased responsiveness to pro-inflammatory signals, aged macrophages also have 
impaired function with reduced phagocytic activity, reduced nitrite burst capacity, and reduced autophagy [38].

Recently, the phenomenon of "inflamm-aging" has been challenged by several studies that have shown decreased macrophage responsiveness to inflammatory signals. Some studies have shown that aged macrophages are less responsive to IFN $\gamma$ and LPS as evident by decreased macrophage-mediated tumoricidal activity and reduced secretion of TNF $\alpha$, IL-1 $\beta$, IL-6, iNOS, and IFN $\gamma$ [42-44]. Though the mechanisms for these changes are still unclear, it has been shown that age-associated decrease in IFN $\gamma$ responsiveness is at least partially mediated by the lack of tyrosine phosphorylation of mitogen-activated protein kinase (MAPK) [45]. Similarly, aged mice highly express miR-146a, a microRNA that negatively regulates IL- $1 \beta$ and IL- 6 via LPS and the nuclear factor kappa-light-chain-enhancer of activated B cells (NFkB) pathways [43]. These differing findings suggest that aged macrophages can be modulated under various conditions and are likely part of a more dynamic interplay among intrinsic aging mechanisms, the microenvironment, and different populations of surrounding cells.

\section{Broader implications}

Given current knowledge, it is apparent that agingassociated changes in the macrophage population are normal events but can also be potential sources for pathological states. As such, modulation of macrophages can provide an avenue for future therapeutics. For example, Slade Shantz et al. demonstrated that blocking macrophage activity by using PLX3397, a drug that blocks the kinase domain of CSF-1R, can accelerate bone callus maturation and subsequent bone formation, illustrating a potential means of enhancing fracture healing and preventing nonunion in the elderly [46]. Several studies showed that aging affects fracture healing in animal models. Histing et al. [47] compared fracture healing in both young and aged senescence-accelerated mice (SAMP6) and senescence-resistance mice (SAMR1). Fracture healing was delayed in aged SAMP6 mice compared with aged SAMR1 mice. The authors concluded that increased osteoclast activity in aged SAMP6 mice was responsible for the difference. However, Egermann et al. [48], using the same model, did not find any differences. Interestingly, using a chimeric model, Xing et al. [49] showed that aged mice receiving juvenile bone marrow cells could accelerate their age-related delay in fracture healing. A decrease in cyclooxygenase 2 (COX-2) expression in the early inflammatory phase of bone repair resulting in delayed remodeling in aged mice was observed by Naik et al. [50]. Lu et al. [51] found a decreased number of chondrocytes expressing collagen II and osteoblasts expressing osteocalcin in middle-aged and elderly mice, compared with younger mice.
With regard to therapy, in order to target age-related inflammation, clinicians have used estrogen to treat a variety of inflammation-mediated conditions, including traumatic injuries [52]. With a better understanding of how macrophages change with age and mediate different disease states, new therapeutics that specifically target these aspects of macrophage function can be developed.

\section{Aging and mesenchymal stem cells}

The use of MSCs and MSC-derived osteoprogenitors in orthopedic surgery is gaining more widespread acceptance. Hernigou et al. pioneered the use of MSC-derived osteoprogenitors to treat osteonecrosis of the hip and other conditions involving bone healing [53]. A recent study extended the use of harvested osteoprogenitors to treat secondary osteonecrosis of the knee with promising results [54]. However, the management and use of MSCs are nuanced, and Prockop [55] has shown that the microenvironment into which MSCs are injected is critical and involves inter-cellular communication via soluble factors and complex cellular interactions. The effect of aging on MSCs is highly relevant, as cell-based therapies for both regeneration and immune modulation are developing rapidly.

\section{Abundance and growth}

As the skeleton ages, the quantity of MSCs in the bone marrow decreases. Quarto et al. [56] compared the number of bone progenitor cells in adult and aged rats and found a significantly decreased number of bone progenitors in the bone marrow with aging. However, Chen [57] observed that the total number of MSCs harvested from mice was significantly higher in older mice (by approximately $20 \%$ ), but the older mice failed to produce as many osteoprogenitor cells compared with younger mice. Using specimens harvested from the iliac crest in healthy patients aged 5 to 70 years, Shigeno and Ashton [58] showed a significant decrease in both the number of precursor cells and degree of proliferation starting in the second and third decades of life. Likewise, Muschler et al. [59] investigated the dependence of nucleated cell and osteoblastic progenitor numbers in bone marrow aspirates on the basis of the age and gender of the patient. Expectedly, the total number of nucleated cells decreased with age regardless of gender, but surprisingly the number of osteoblastic progenitors did not decrease significantly for men whereas it did for women. Moreover, Stolzing et al. [60] also found a decrease in the number and proliferative capacity of MSCs harvested in older humans. Taken together, these data indicate that aging decreases the availability and growth potential of MSCs for bone formation. Furthermore, these changes may be dependent on the sex of the host. 


\section{Differentiation, effectiveness, and intrinsic changes}

The potential for differentiation of MSCs according to age is controversial, but most of the studies have shown a decrease in their capacity to undergo osteogenic differentiation. Baxter et al. [61] harvested human MSCs (hMSCs) from donors aged 0 to $18\left(\mathrm{hMSCs}_{0-18}\right)$ and 59

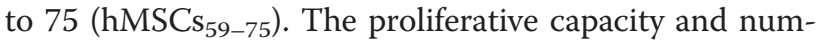
ber of colony-forming-unit alkaline phosphatase-positive $\left(\mathrm{CFU}-\mathrm{ALP}^{+}\right)$cells were decreased in $\mathrm{hMSCs}_{59-75}$. The authors also measured the mean telomere restriction fragment (mTRF), which can be used to estimate the remaining replicative capacity of a cell population. They found that mTRF in $\mathrm{hMSCs}_{0-18}$ was significantly longer than in hMSCs $_{59-75}$. In another study, Zhou et al. [62] reported on cultured hMSCs from donors aged 17 to 90 . Aged hMSCs showed increased numbers of senescenceassociated $\beta$-galactosidase (SA- $\beta$-gal)-positive cells, apoptotic cells, a decreased proliferation rate, and $\mathrm{ALP}^{+}$ cells. Aged hMSCs also experienced genetic flaws with overexpression of $p 53$ and its target $p 21$ and $B A X$ (apoptosis regulator) genes (apoptotic pathway). Kuehn [63] also reported major genetic flaws such as chromosomal rearrangement or overexpression of the $M Y C$ oncogene. Similarly, D'Ippolito et al. [64] found significantly fewer CFU-ALP ${ }^{+}$cells in cultured MSCs from vertebral bone marrow from older donors. A potential explanation of the failure of aged MSCs to differentiate may be due to shortening of telomere length. To test this hypothesis, Liu et al. compared telomerase knockout MSCs (mTR ${ }^{-1-}$ MSCs) to wild-type MSCs (WT-MSCs) [65]. Their results showed a complete failure of $\mathrm{mTR}^{-/-} \mathrm{MSCs}$ to differentiate into chondrocytes. Moreover, $\mathrm{mTR}^{-1-} \mathrm{MSCs}$ experienced early morphologic alterations. Pignolo et al. [66] also validated this hypothesis by using a mouse model of Werner syndrome (premature aging). The role of cell cycle regulators has been shown to be critical for the regulation of cellular senescence. Among the cell cycle regulators, $\mathrm{p} 16^{\mathrm{INK} 4 \mathrm{~A}}$, which interferes with CDK4 and CDK6 cell cycle kinases, was found to be overexpressed in aged hMSCs [67].

Wound healing is also affected by senescence. Choudhery et al. [68], in an in vitro study, showed decreased wound-healing abilities with murine MSCs (mMSCs) harvested from aged mice. Interestingly, they also found a downregulation of vascular endothelial growth factor (VEGF), stromal cell-derived factor 1 chemokine (SDF-1), and protein kinase B (which is known to inhibit apoptosis) expression in aged mMSCs. Angiogenic potential was also dramatically decreased in aged mMSCs. The potential for regeneration of muscle by MSCs is also profoundly affected by senescence. Resident muscle MSCs, also known as satellite cells, lose their selfrenewal abilities via alterations in FGF receptor 1 and p38 $\alpha \beta$ MAPK signaling, as shown by Bernet et al. [69].

\section{Conclusions}

With aging, the proliferative and functional abilities of macrophages and MSCs are impaired because of a combination of intrinsic and environmental factors. As proper bone healing requires an inflammatory phase, the increased survival of anti-inflammatory M2 macrophages and reduced secretion of pro-inflammatory factors with age may jeopardize timely bone regeneration. At the same time, aging negatively impacts MSC proliferation and differentiation, further impeding the bone-healing process. It would appear that, taken together, both macrophages and MSCs, cells critical for regeneration of musculoskeletal tissues, are adversely affected by aging. This scenario provides new opportunities for modulation of cellular events in order to optimize the healing of mesenchymally derived tissues, including bone.

\section{Abbreviations}

ALP: Alkaline phosphatase; BMDM: Bone marrow-derived macrophage: CCL1: Chemokine (C-C motif) ligand 1; CCL18: Chemokine (C-C motif) ligand 18; CCR2: C-C chemokine receptor type 2; CCR7: C-C chemokine receptor type 7; CD163: Cluster of differentiation 163; CD206: Cluster of differentiation 206; CDK: Cyclin-dependent kinase; CFU-ALP ${ }^{+}$: Colony-forming-unit alkaline phosphatase-positive; CSF-1R: Colony-stimulating factor 1 receptor; CXCR4: C-X-C chemokine receptor type 4; FGF: Fibroblast growth factor; FIZZ1: Found in inflammatory zone protein; GM-CSF: Granulocyte macrophage colony-stimulating factor; HLA-DR: Human leukocyte antigen-antigen D related; hMSC: Human mesenchymal stem cell; IFNy: Interferon gamma; IL: Interleukin; iNOS: Inducible nitric oxide synthase; LPS: Lipopolysaccharide; MAPK: Mitogen-activated protein kinase; MCP-1: Monocyte chemotactic protein-1; miR-146a: Microrna-146a; mMSC: Murine mesenchymal stem cell; MSC: Mesenchymal stem cell; mTRF: Mean telomere restriction fragment; MYC: Myelocytomatosis; NOS2: Nitric oxide synthase 2; SAMP6: Senescence-accelerated mice; SAMR1: Senescenceresistance mice; SDF-1: Stromal cell-derived factor 1; STAT5a: Signal transducer and activator of transcription 5A; TLR: Toll-like receptor; TNFa: Tumor necrosis factor-alpha; WT-MSC: Wild-type mesenchymal stem cell.

\section{Competing interests}

The authors declare that they have no competing interests.

\section{Authors' contributions}

EG has made substantial contributions to conception and design, or acquisition of data, or analysis and interpretation of data. LL has been involved in drafting the manuscript and revising it critically for important intellectual content. SBG has also been involved in revising the manuscript and adding important intellectual content, as well as given final approval of the version to be published. All authors read and approved the final manuscript.

\section{Acknowledgments}

This work was supported in part by grants 2R01AR055650 and 1R01AR063717 from National Institute of Arthritis and Musculoskeletal and Skin Diseases at the National Institutes of Health.

\section{Author details}

${ }^{1}$ Department of Orthopaedic Surgery, Stanford University, R116, 300 Pasteur Drive, Stanford, CA 94305, USA. ² Laboratoire de Biomécanique et Biomatériaux Ostéo-Articulaires - UMR CNRS 7052, Faculté de Médecine - Université Paris7, 10 avenue de Verdun, 75010 Paris, France. ${ }^{3}$ Department of Orthopaedic Surgery, Hopital Cochin, APHP, Université Paris5, 27 rue du Faubourg Saint-Jacques, 75014 Paris, France.

Published online: 22 March 2016 


\section{References}

1. UScensus. U.S. Department of Commerce, Economics and Statistics Administration, U.S. Census Bureau, Washington. 2010. http://www.census. gov/prod/cen2010/briefs/c2010br-09.pdf. Accessed 29 July 2015.

2. Iorio R, Robb WJ, Healy WL, Berry DJ, Hozack WJ, Kyle RF, et al. Orthopaedic surgeon workforce and volume assessment for total hip and knee replacement in the United States: preparing for an epidemic. J Bone Joint Surg Am. 2008;90:1598-605.

3. UScensus. U.S. Department of Commerce, Economics and Statistics Administration, U.S. Census Bureau, Washington. 2015. http://www.census. gov/content/dam/Census/library/publications/2015/demo/p25-1143.pdf Accessed 29 July 2015.

4. Office of the Surgeon General (US). Bone Health and Osteoporosis: A Report of the Surgeon General. Rockville (MD): Office of the Surgeon General (US); 2004. 5, The Burden of Bone Disease. Available from: http://www.ncbi.nlm. nih.gov/books/NBK45502/. Accessed 29 July 2015.

5. Einhorn TA, Majeska RJ, Rush EB, Levine PM, Horowitz MC. The expression of cytokine activity by fracture callus. J Bone Miner Res. 1995;10:1272-81.

6. Gerstenfeld LC, Cho TJ, Kon T, Aizawa T, Cruceta J, Graves BD, et al. Impaired intramembranous bone formation during bone repair in the absence of tumor necrosis factor-alpha signaling. Cells Tissues Organs (Print). 2001;169:285-94.

7. Xing Z, Lu C, Hu D, Yu Y-y, Wang X, Colnot C, et al. Multiple roles for CCR2 during fracture healing. Dis Model Mech. 2010;3:451-8.

8. Cho SW. Role of osteal macrophages in bone metabolism. J Pathol Transl Med. 2015;49:102-4.

9. Cho SW, Soki FN, Koh A, Eber MR, Entezami P, Park SI, et al. Osteal macrophages support physiologic skeletal remodeling and anabolic actions of parathyroid hormone in bone. Proc Natl Acad Sci U S A. 2014;111:1545-50.

10. Alexander KA, Chang MK, Maylin ER, Kohler T, Müller R, Wu AC, et al. Osteal macrophages promote in vivo intramembranous bone healing in a mouse tibial injury model. J Bone Miner Res. 2011;26:1517-32.

11. Pettit AR, Chang MK, Hume DA, Raggatt L-J. Osteal macrophages: a new twist on coupling during bone dynamics. Bone. 2008;43:976-82.

12. Chang MK, Raggatt L-J, Alexander KA, Kuliwaba JS, Fazzalari NL, Schroder K, et al. Osteal tissue macrophages are intercalated throughout human and mouse bone lining tissues and regulate osteoblast function in vitro and in vivo. J Immunol. 2008;181:1232-44.

13. Phillips AM. Overview of the fracture healing cascade. Injury. 2005;36 Suppl 3:S5-7.

14. Ito $\mathrm{H}$. Chemokines in mesenchymal stem cell therapy for bone repair: a novel concept of recruiting mesenchymal stem cells and the possible cell sources. Mod Rheumatol. 2011;21:113-21.

15. Shinohara K, Greenfield S, Pan H, Vasanji A, Kumagai K, Midura RJ, et al. Stromal cell-derived factor-1 and monocyte chemotactic protein-3 improve recruitment of osteogenic cells into sites of musculoskeletal repair. J Orthop Res. 2011;29:1064-9.

16. Kitaori T, Ito H, Schwarz EM, Tsutsumi R, Yoshitomi H, Oishi S, et al. Stromal cell-derived factor $1 /$ CXCR4 signaling is critical for the recruitment of mesenchymal stem cells to the fracture site during skeletal repair in a mouse model. Arthritis Rheum. 2009;60:813-23.

17. Granero-Molto F, Weis JA, Miga MI, Landis B, Myers TJ, O'Rear L, et al. Regenerative effects of transplanted mesenchymal stem cells in fracture healing. Stem Cells. 2009;27:1887-98.

18. Otsuru S, Tamai K, Yamazaki T, Yoshikawa H, Kaneda Y. Circulating bone marrow-derived osteoblast progenitor cells are recruited to the boneforming site by the CXCR4/stromal cell-derived factor-1 pathway. Stem Cells (Dayton, Ohio). 2008;26:223-34

19. Colnot C. Skeletal cell fate decisions within periosteum and bone marrow during bone regeneration. J Bone Miner Res. 2009;24:274-82.

20. Kumagai K, Vasanji A, Drazba JA, Butler RS, Muschler GF. Circulating cells with osteogenic potential are physiologically mobilized into the fracture healing site in the parabiotic mice model. J Orthop Res. 2008;26:165-75.

21. Ren PG, Huang Z, Ma T, Biswal S, Smith RL, Goodman SB. Surveillance of systemic trafficking of macrophages induced by UHMWPE particles in nude mice by noninvasive imaging. J Biomed Mater Res A. 2010;94:706-11.

22. Davies LC, Jenkins SJ, Allen JE, Taylor PR. Tissue-resident macrophages. Nat Immunol. 2013;14:986-95.

23. Mantovani A, Sica A, Sozzani S, Allavena P, Vecchi A, Locati M. The chemokine system in diverse forms of macrophage activation and polarization. Trends Immunol. 2004;25:677-86.
24. Valladares RD, Nich C, Zwingenberger S, Li C, Swank KR, Gibon E, et al. Toll-like receptors-2 and 4 are overexpressed in an experimental model of particle-induced osteolysis. J Biomed Mater Res A. 2014;102:3004-11.

25. Rao AJ, Gibon E, Ma T, Yao Z, Smith RL, Goodman SB. Revision joint replacement, wear particles, and macrophage polarization. Acta Biomater. 2012:8:2815-23.

26. Martinez FO, Sica A, Mantovani A, Locati M. Macrophage activation and polarization. Front Biosci. 2008;13:453-61.

27. Guihard P, Boutet MA, Brounais-Le Royer B, Gamblin AL, Amiaud J, Renaud A, et al. Oncostatin $m$, an inflammatory cytokine produced by macrophages, supports intramembranous bone healing in a mouse model of tibia injury. Am J Pathol. 2015;185:765-75.

28. Maresz K, Ponomarev ED, Barteneva N, Tan Y, Mann MK, Dittel BN. IL-13 induces the expression of the alternative activation marker $Y m 1$ in a subset of testicular macrophages. J Reprod Immunol. 2008;78:140-8.

29. Nair MG, Du Y, Perrigoue JG, Zaph C, Taylor JJ, Goldschmidt M, et al. Alternatively activated macrophage-derived RELM-alpha is a negative regulator of type 2 inflammation in the lung. J Exp Med. 2009;206:937-52.

30. Wang Y, Wehling-Henricks M, Samengo G, Tidball JG. Increases of M2a macrophages and fibrosis in aging muscle are influenced by bone marrow aging and negatively regulated by muscle-derived nitric oxide. Aging Cell. 2015;14:678-88

31. Sebastian C, Herrero C, Serra M, Lloberas J, Blasco MA, Celada A. Telomere shortening and oxidative stress in aged macrophages results in impaired STAT5a phosphorylation. J Immunol. 2009;183:2356-64.

32. Aristorena M, Blanco FJ, de Las C-EM, Ojeda-Fernandez L, Gallardo-Vara E, Corbi $\mathrm{A}$, et al. Expression of endoglin isoforms in the myeloid lineage and their role during aging and macrophage polarization. J Cell Sci. 2014;127(Pt 12):2723-35.

33. Ramanathan R, Kohli A, Ingaramo MC, Jain A, Leng SX, Punjabi NM, et al. Serum chitotriosidase, a putative marker of chronically activated macrophages, increases with normal aging. J Gerontol A Biol Sci Med Sci. 2013;68:1303-9.

34. Herrero C, Marques L, Lloberas J, Celada A. IFN-gamma-dependent transcription of MHC class II IA is impaired in macrophages from aged mice. J Clin Invest. 2001:107:485-93.

35. Gomez CR, Acuna-Castillo C, Nishimura S, Perez V, Escobar A, Salazar-Onfray $F$, et al. Serum from aged F344 rats conditions the activation of young macrophages. Mech Ageing Dev. 2006;127:257-63.

36. Linehan E, Dombrowski Y, Snoddy R, Fallon PG, Kissenpfennig A, Fitzgerald DC. Aging impairs peritoneal but not bone marrow-derived macrophage phagocytosis. Aging Cell. 2014;13:699-708.

37. Barrett JP, Costello DA, O'Sullivan J, Cowley TR, Lynch MA. Bone marrow-derived macrophages from aged rats are more responsive to inflammatory stimuli. J Neuroinflammation. 2015;12:67.

38. Stranks AJ, Hansen AL, Panse I, Mortensen M, Ferguson DJ, Puleston DJ, et al. Autophagy controls acquisition of aging features in macrophages. J Innate Immun. 2015;7:375-91

39. Cecílio CA, Costa EH, Simioni PU, Gabriel DL, Tamashiro WM. Aging alters the production of iNOS, arginase and cytokines in murine macrophages. Braz J Med Biol Res. 2011;44:671-81.

40. Dimitrijevic M, Stanojevic S, Vujic V, Aleksic I, Pilipovic I, Leposavic G. Aging oppositely affects TNF- $a$ and IL-10 production by macrophages from different rat strains. Biogerontology. 2014;15:475-86.

41. Smallwood HS, Lopez-Ferrer D, Squier TC. Aging enhances the production of reactive oxygen species and bactericidal activity in peritoneal macrophages by upregulating classical activation pathways. Biochemistry. 2011;50:9911-22.

42. Ramirez A, Rathinam V, Fitzgerald KA, Golenbock DT, Mathew A. Defective pro-IL-1 $\beta$ responses in macrophages from aged mice. Immun Ageing. 2012;9:27.

43. Jiang $M$, Xiang $Y$, Wang D, Gao J, Liu D, Liu Y, et al. Dysregulated expression of miR-146a contributes to age-related dysfunction of macrophages. Aging Cell. 2012;11:29-40.

44. Mahbub S, Deburghgraeve CR, Kovacs EJ. Advanced age impairs macrophage polarization. J Interferon Cytokine Res. 2012;32:18-26.

45. Ding A, Hwang S, Schwab R. Effect of aging on murine macrophages. Diminished response to IFN-gamma for enhanced oxidative metabolism. J Immunol. 1994:153:2146-52.

46. Slade Shantz JA, Yu Y-Y, Andres W, Miclau T, Marcucio R. Modulation of macrophage activity during fracture repair has differential effects in young adult and elderly mice. J Orthop Trauma. 2014;28 Suppl 1:S10-4. 
47. Histing T, Kuntz S, Stenger D, Scheuer C, Garcia P, Holstein JH, et al. Delayed fracture healing in aged senescence-accelerated P6 mice. J Invest Surg. 2013;26:30-5.

48. Egermann M, Heil P, Tami A, Ito K, Janicki P, Von Rechenberg B, et al. Influence of defective bone marrow osteogenesis on fracture repair in an experimental model of senile osteoporosis. J Orthop Res. 2010;28:798-804.

49. Xing Z, Lu C, Hu D, Miclau T, Marcucio RS. Rejuvenation of the inflammatory system stimulates fracture repair in aged mice. J Orthop Res. 2010;28:1000-6.

50. Naik AA, Xie C, Zuscik MJ, Kingsley P, Schwarz EM, Awad H, et al. Reduced COX-2 expression in aged mice is associated with impaired fracture healing. J Bone Miner Res. 2009;24:251-64.

51. Lu C, Miclau T, Hu D, Hansen E, Tsui K, Puttlitz C, et al. Cellular basis for age-related changes in fracture repair. J Orthop Res. 2005;23:1300-7.

52. Kovacs EJ. Aging, traumatic injury, and estrogen treatment. Exp Gerontol. 2005:40:549-55.

53. Hernigou P, Poignard A, Zilber S, Rouard H. Cell therapy of hip osteonecrosis with autologous bone marrow grafting. Indian J Orthop. 2009;43:40-5

54. Goodman SB, Hwang KL. Treatment of secondary osteonecrosis of the knee with local debridement and osteoprogenitor cell grafting. J Arthroplasty. 2015;30:1892-6.

55. Prockop DJ. Repair of tissues by adult stem/progenitor cells (MSCs): controversies, myths, and changing paradigms. Mol Ther. 2009;17:939-46.

56. Quarto R, Thomas D, Liang CT. Bone progenitor cell deficits and the age-associated decline in bone repair capacity. Calcif Tissue Int. 1995:56:123-9.

57. Chen TL. Inhibition of growth and differentiation of osteoprogenitors in mouse bone marrow stromal cell cultures by increased donor age and glucocorticoid treatment. Bone. 2004;35:83-95.

58. Shigeno Y, Ashton BA. Human bone-cell proliferation in vitro decreases with human donor age. J Bone Joint Surg (Br). 1995;77:139-42.

59. Muschler GF, Nitto H, Boehm CA, Easley KA. Age- and gender-related changes in the cellularity of human bone marrow and the prevalence of osteoblastic progenitors. J Orthop Res. 2001;19:117-25.

60. Stolzing A, Jones E, McGonagle D, Scutt A. Age-related changes in human bone marrow-derived mesenchymal stem cells: consequences for cell therapies. Mech Ageing Dev. 2008;129:163-73.

61. Baxter MA, Wynn RF, Jowitt SN, Wraith JE, Fairbairn LJ, Bellantuono I. Study of telomere length reveals rapid aging of human marrow stromal cells following in vitro expansion. Stem Cells. 2004;22:675-82.

62. Zhou S, Greenberger JS, Epperly MW, Goff JP, Adler C, Leboff MS, et al. Agerelated intrinsic changes in human bone-marrow-derived mesenchymal stem cells and their differentiation to osteoblasts. Aging Cell. 2008;7:335-43.

63. Kuehn BM. Genetic flaws found in aging stem cell lines. JAMA. 2005;294: 1883-4.

64. D'I'ppolito G, Schiller PC, Ricordi C, Roos BA, Howard GA. Age-related osteogenic potential of mesenchymal stromal stem cells from human vertebral bone marrow. J Bone Miner Res. 1999:14:1115-22.

65. Liu L, DiGirolamo CM, Navarro PAAS, Blasco MA, Keefe DL. Telomerase deficiency impairs differentiation of mesenchymal stem cells. Exp Cell Res. 2004;294:1-8.

66. Pignolo RJ, Suda RK, McMillan EA, Shen J, Lee S-H, Choi Y, et al. Defects in telomere maintenance molecules impair osteoblast differentiation and promote osteoporosis. Aging Cell. 2008;7:23-31.

67. Shibata KR, Aoyama T, Shima Y, Fukiage K, Otsuka S, Furu M, et al. Expression of the p16INK4A gene is associated closely with senescence of human mesenchymal stem cells and is potentially silenced by DNA methylation during in vitro expansion. Stem Cells. 2007;25:2371-82.

68. Choudhery MS, Khan M, Mahmood R, Mehmood A, Khan SN, Riazuddin S. Bone marrow derived mesenchymal stem cells from aged mice have reduced wound healing, angiogenesis, proliferation and anti-apoptosis capabilities. Cell Biol Int. 2012;36:747-53.

69. Bernet JD, Doles JD, Hall JK, Kelly Tanaka K, Carter TA, et al. p38 MAPK signaling underlies a cell-autonomous loss of stem cell self-renewal in skeletal muscle of aged mice. Nat Med. 2014;20:265-71. 